\title{
CORRIGENDUM
}

\section{Usefulness of motion sensors to estimate energy expenditure in children and adults: a narrative review of studies using DLW}

LB Sardinha and PB Júdice

European Journal of Clinical Nutrition (2017) 71, 1026; doi:10.1038/ejcn.2017.78

Correction to: European Journal of Clinical Nutrition (2017) 71, 331-339. doi:10.1038/ejcn.2017.2; published online 1 February 2017

Since the publication of this article, the authors have noticed a problem within the citations and two references were missing. The correct references are listed below. These were unintentional errors on our part and we apologise for the indicated mistakes.

1) A reference to 'van Hees VT. (2013). Implementation of raw accelerometry in physical activity epidemiology (Doctoral dissertation). Retrieved from Research Gate. DOI:10.13140/ RG.2.1.3314.7766' has been added to the sentence 'Raw accelerometry distinguishes itself from traditional accelerometry in that it measures body acceleration in non-brand specific ' $g$-units' at a sample frequency at least twice above the maximum frequency of interest. Here, 'g-units' refers to the sensor's calibration against gravitational acceleration. One ' $g$ ' equals about $9.81 \mathrm{~m} / \mathrm{s}^{2}$ subject to global latitude. ${ }^{6}$

2) Reference 10 (Crouter SE, Clowers KG, Bassett DR Jr. A novel method for using accelerometer data to predict energy expenditure. J Appl Physiol 2006; 100: 1324-1331) has been replaced by the correct reference (Lyden K, Kozey SL, Staudenmeyer JW, Freedson, PS. A comprehensive evaluation of commonly used accelerometer energy expenditure and MET prediction equations. Eur J Appl Physiol 2011; 111: 187-201).
Editor's note to corrigendum:

The ethics of research and its publication covers several domains. We and others have engaged the readership on our views $(1,2)$, in our continued drive to promote the best science that is conducted and reported above reproach. Our reviewers do an exceptional job and they have our full support. Plagiarism is not tolerated by the EJCN but despite our best in-house efforts at screening, sometimes there is a slip up. When brought to our attention, the necessary steps were immediately taken and have resulted in a correction and an apology by the authors. This was an honest oversight. Having reviewed this case in its entirety, we have decided not to retract this publication. In this instance we are grateful for the timely detection and intimation by a member of our scientific community. We value such a relationship and have always believed our readership plays as much an important role in demanding ethical science, as we do (2).

1. Müller MJ, Landsberg B, Ried J. Fraud in science: a plea for a new culture in research. Eur J Clin Nutr 2014; 68: 411-415.

2. Müller MJ, Soares MJ. The ethics of research publication. Eur J Clin Nutr 2017; 71: doi:10.1038/ejcn.2017.20.

Signed by: Soares MJ, Muller MJ \& Bosy-Westphal A (Guest Editor) 